\title{
Voltametric Characterization of Composite Silicon- Carbon Electrode in Presence of Indigo Carmine
}

\author{
N'Dri Seiny Roger ${ }^{1,2}$, Coulibaly Mariame ${ }^{1}$, Yao N'Guessan Alfred ${ }^{1}$ \\ ${ }^{1}$ Laboratoire des Sciences Physiques Fondamentales et Appliquées, Ecole Normale Supérieure08 BP 10 Abidjan, Côte d'Ivoire \\ ${ }^{2}$ Laboratoire de Physique de la matière condensée et technologie, Université Félix Houphouët Boigny de Cocody, 01 BP V 3, Abidjan, Côte \\ d'Ivoire
}

\begin{abstract}
The fight against pollution by heavy metals requires the establishment of reliable and inexpensive simple techniques. Electrochemical sensors offer innovative solutions provided you have active materials sensitive layer. This layer must have in his surface selective groups facing metalliccations. More organo-mineral composite materials are used in electroanalysis. Here silicon is incorporated into the carbon graphite conductive matrix. The silicon-carbon composite material has active sites in electroanalysis in the presence of indigo carmine.
\end{abstract}

Keywords: electrochemical sensor, sensitive layer, silicon-carbon, indigo carmine

\section{Introduction}

The use of new materials in electroanalysis is constantly changing. The research of active materials for the metallic pollutants detection has led in recent decades organomineral composites. Most of these materials uses the carbon graphite as a conductive matrix in which is incorporated the other in a small proportion materials such as inorganic materials. Therefore carbon graphite mixed with silica was activated by thiol groups [1]-[3] or dithiocarbamates [4],[5] or carbamoylphosphonique group [6] and used to preconcentrate heavy metals such as copper (II) [7]-[9], mercury (II) [7],[10 ]-[11] cadmium (II) [6], and lead (II) [6]. So have we seen the rise of carbon zeolite clay mixture for the formation of selective sensors facing some harmful inorganic compounds [12].

Our approach is innovative. It aims at introducing in electroanalysis silicon inorganic material, semiconductor used in the manufacture of photovoltaic cells. It is up to silicate materials. The reactivity of these materials comes mainly from their surface properties [7] which sit two large functional families: siloxane groups $(\equiv \mathrm{Si}-\mathrm{O}-\mathrm{Si} \equiv)$ and silanol groups ( $\equiv \mathrm{Si}-\mathrm{OH})$. Among these groups, the silanol is more reactive face to metallic cations such as copper (II) [7] and mercury (II) [11].

Therefore the use of silicon based in this study as new organo-mineral material proposed in electroanalysis. The monomer used here as a material modifying the surface of the electrodes is the dye indigo carmine (IC, 3, 3 dioxo-2, 2 bis-indolyden-5, 5-disulfonic aciddisodiumsalt).

\section{Experimental}

\subsection{Equipment}

Electrochemical experiments were performed with a potentiostat (PalmSens, Ecochemie, Netherlands) Controlled by the pstrace software and computer controlled.The analytical method is voltammetry (cyclic and differential pulse). The carbon paste electrode (or mixture of silicon- carbon) was used as working electrode (W). The electrode $\mathrm{Ag} / \mathrm{AgCl} / \mathrm{KCl}$ at is used as a reference electrode ( $\mathrm{R})$ and platinum as counter-electrode (C). The $\mathrm{pH}$ of the solutions is measured with the $\mathrm{pH}$ meter (Hanna Instruments, USA)

\subsection{Reagents and materials}

All chemicals used were of analytical grade. They are prepared with distilled water. Graphite powder $(\Phi=$ $0.22 \mu \mathrm{m})$ is from SIGMA-ALDRICH. Silicon is of PHOTOWATT SA. The indigo carmine was delivered by Aldrich Company. Paraffin oil is of DP-PHARMA, sodium hydroxide $(\mathrm{NaOH})$ of Sharlau and hydrochloric acid $(37 \%, \mathrm{~d}$ $=1.9$ ) of chemistry more.

\subsection{Development of the carbon paste electrode}

The carbon paste working electrode is prepared from the black graphite powder mixed with a hydrophobic binder and inactive: paraffin oil. The paraffin oil is mixed in the proportion of $0.3 \mathrm{ml}$ per $1 \mathrm{~g}$ of graphite. The mixture is pounded in a mortar with a pestle for a smooth paste. The mixed dough is put into the body of the geometric electrode area $0.07 \mathrm{~cm}^{2}$. It is regenerated by regularly wiping on clean and smooth paper.

2.4. Development of composite silicon-carbon paste electrode

The composite electrode is obtained by mixing the silicon in the proportion of $10 \%$ of the mass of carbon. To this mixture is added to the paraffin oil at the amount of $0.3 \mathrm{ml}$ per gram of carbon. The mixture is pounded in a mortar to make the homogeneous paste.The active electrode surface is regenerated by a regular wipe on clean and smooth paper. The paste is renewed after each measurement.

\subsection{Procedure}

The carbon paste working electrode (or mixture of siliconcarbon) and the other electrodes are immersed in the 


\section{International Journal of Science and Research (IJSR) \\ ISSN (Online): 2319-7064}

Index Copernicus Value (2013): 6.14 | Impact Factor (2015): 6.391

electrolytic solution of indigo carmine.The measurements are performed at room temperature.

\section{Results and Discussion}

The characterizations of materials implanted in the electrodes are studiedin cyclic voltammetry. The study is done in two $\mathrm{pH}$ values of the electrolyte solutions of indigo carmine.

\subsection{Characterization of the carbon paste electrode in contact with indigo carmine}

\subsubsection{Electrochemical behaviour}

The voltammograms obtained in an acid medium at $\mathrm{pH}=3$ (a) and in a basic medium at $\mathrm{pH}=10$ (b) are shown in Figure 1.
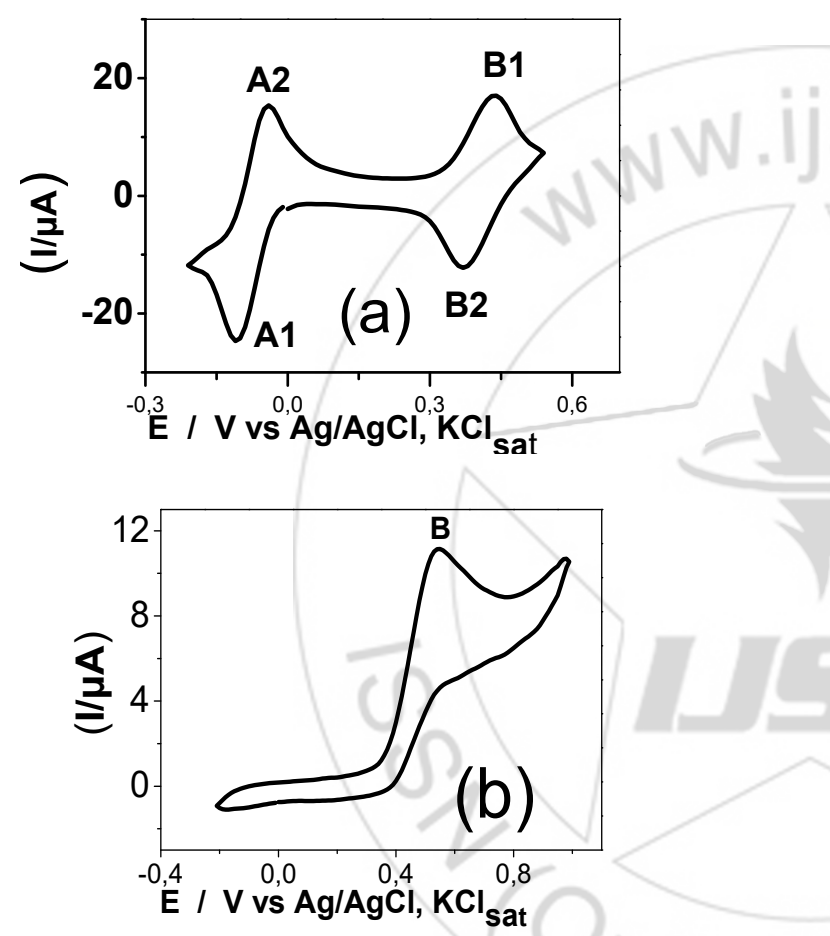

Figure 1: Electrochemical behaviour of indigo carmine on the carbon paste electrode, (a) an acid medium $(\mathrm{pH}=3)$, scan rate $80 \mathrm{mV} / \mathrm{s}$, (b) alkaline medium $(\mathrm{pH}=10)$, scan rate $60 \mathrm{mV} / \mathrm{s}$.

In the alkaline medium $\mathrm{pH}=10$ (Figure 1b), it appears an irreversible redox peak $\mathrm{B}$. This peak $\mathrm{B}$ reflects the oxidation of indigo carmine in dehydroindigo carmine (DHIC) [13]. The product of oxidation is a positive bipolaron. It appears at the potential Eappl $=0.45 \mathrm{~V}$.In acid medium $\mathrm{pH}=3$ (Figure 1a), it appears two redox peaks A and B reversible. These peaks obey the law of Nertz. We distinguish:

- Peak A (A1 and A2), that reflects the reduction of indigo carmine in leucoindigo carmine and oxidation of leucoindigo carmine (negative bipolaron) in indigo carmine.

- Peak B (B1 and B2), that indicates the oxidation of the indigo carmine in dehydroindigo carmine (DHIC) and reduction of DHIC in indigo carmine. This redox reaction of indigo carmine in acid medium takes place in two steps. The mechanism reaction as proposed by Fanjul- Bolado and al is the following scheme 1 [13].
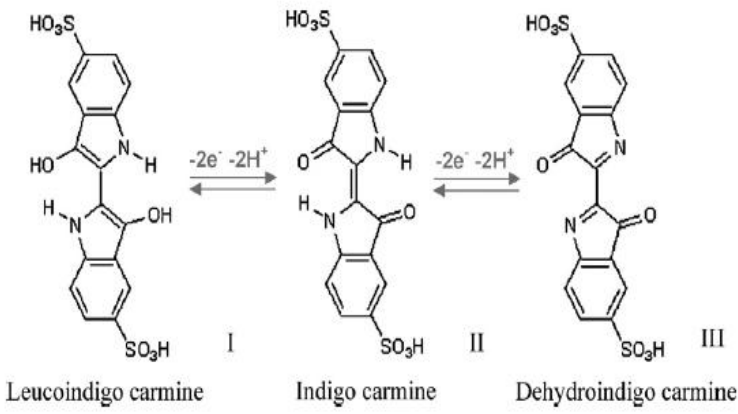

Scheme 1: Mechanism of oxidation-reduction of indigo carmine in an acid medium [13].

The potential differences between different peaks, the ratio between the anodic and cathodic currents, as well as the formal potential deducted from figure 1a in acid medium are contained in table 1. Such as Fanjul-Bolado and al [13] and Jian -Bo and al [15], our values of $\Delta \mathrm{Ep}>57 / \mathrm{n}(\mathrm{mV})$ [15] (n represents the number of generated electrons), indicating that the kinetics of the reaction is quasi-reversible. Similarly the current ratio greater than unity, suggests that a material transport phenomenon is coupled to the redox reaction.

Table 1: Parameters of the electrochemical response of indigo carmine on the carbon paste electrode (scan rate 80 $\mathrm{mV} / \mathrm{s}$ at $\mathrm{pH}=3$ )

\begin{tabular}{|c|c|c|c|c|}
\hline Redox couples & \multicolumn{2}{|c|}{$\Delta \mathrm{Ep}(\mathrm{mV})$} & $\mathrm{E}_{0}(\mathrm{mV})$ & $\mathrm{Ia} / \mathrm{Ic}$ \\
\hline $\mathrm{A} 1 / \mathrm{A} 2$ & 30 & $39-41[\mathbf{1 3}]$ & -25 & 1,07 \\
\hline $\mathrm{B} 1 / \mathrm{B} 2$ & 50 & $25-57[\mathbf{1 5}]$ & 400 & 1,2 \\
\hline
\end{tabular}

$\mathbf{E}_{0}=(\mathbf{E p a}+\mathbf{E p c}) / 2$ $\Delta \mathbf{E p}=\mathbf{E p a}-\mathbf{E p c}$

\subsubsection{Study based on the number of cycles}

The voltammograms of this study are presented in Figure 2. In acid medium $\mathrm{pH}=3$ (Figure $2 \mathrm{a}$ ), the amplitude peak B1/B2 increases with the number of cycles, whereas the peak of A1/A2 remains unchanged. Increasing the amplitude of the peak $B$ indicates the existence of a conductive polymer.

In the alkaline medium $\mathrm{pH}=10(2 \mathrm{~b})$, increasing the number of cycles does not affect the amplitude of the single peak $\mathrm{B}$ as also shown Jian-Bo and al [15], and Coulibaly and al [ 14] with indigo carmine. The resulting polymer is adsorbed to the surface of electrodes; it is a physical adsorption which emphasizes low energy type Van der Waals [16]. The electronic transfer mode is the inner sphere [16].

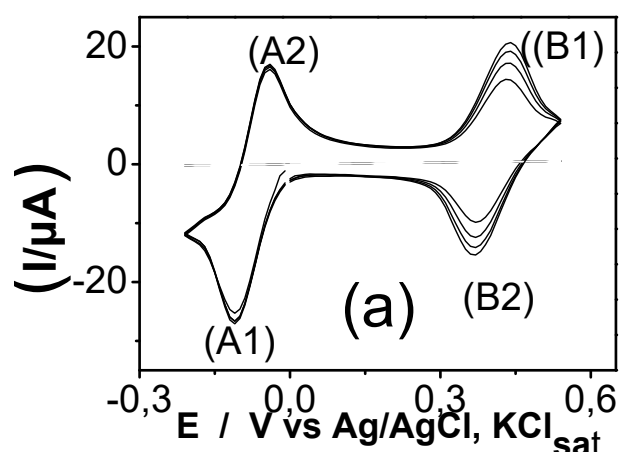




\section{International Journal of Science and Research (IJSR) \\ ISSN (Online): 2319-7064}

Index Copernicus Value (2013): 6.14 | Impact Factor (2015): 6.391

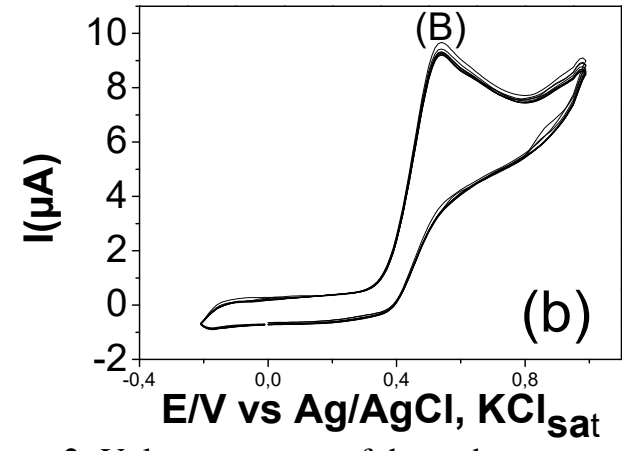

Figure 2: Voltammograms of the carbon paste electrode in an indigo carmine solution: (a) $\mathrm{pH}=3 \mathrm{scan}$ rate $80 \mathrm{mV} / \mathrm{s}$, (b) a $\mathrm{pH}=10$, scan rate $60 \mathrm{mV} / \mathrm{s}$.

\subsubsection{Polymer gap calculation}

The gaps of the polymers are calculated by several methods such as quantum methods: Method of Hartree-FockRoothaan, Methods Post-SCF, Density functional theory (DFT) etc .... [17].

Cyclic voltammetry is recognized as an easy and effective approach to assessing the position of the energy levels of the HOMO (Highest Occupied Molecular Orbital) and LUMO (Lowest Unoccupied Molecular Orbital).

The method of Bredas and al [18] permit to calculate the theoretical energy levelsof the HOMO and LUMO and thus the gap.

This calculation allows the classification of polymers from reactions by isolating or semiconductors. The calculation of the energy levels and the gap in acidic medium polymers (Figure 1a) obtained with the method of Bredas are contained in Table 2. The gap values obtained are less than $1 \mathrm{eV}$; this indicates that indigo carmine is an organic semiconductor [19].

In basic medium it appears that the peak of the oxidation of indigo carmine in dehydroindigo carmine. The value of the $\mathrm{HOMO}$ of the single peak B (Figure $1 \mathrm{~b}$ ) is $-5 \mathrm{eV}$.

Table 2: Energy levels and value of the gap redox couples indigo carmine acid medium $\mathrm{pH}=3$

\begin{tabular}{|c|c|c|c|}
\hline Pics & Energy levels & Values (eV) & $\begin{array}{c}\text { Gap value } \\
\text { Eg (eV) }\end{array}$ \\
\hline \multirow{2}{*}{ A1/A2 } & HOMO & -4.5 & \multirow{2}{*}{0.065} \\
\cline { 2 - 3 } & LUMO & -4.565 & \multirow{2}{*}{0.15} \\
\hline \multirow{2}{*}{ B1/B2 } & HOMO & -4.9 & -5.05 \\
\cline { 2 - 3 } & LUMO & \multicolumn{2}{|c}{} \\
\hline
\end{tabular}

3.2. Characterization of the composite silicon-carbon electrode in contact with the electrolytic solutions of indigo carmine.

\subsubsection{Electrochemical behaviour.}

The electrochemical behaviour of indigo carmine was studied with the organo-mineral silicon-carbon electrode. The voltammograms obtained in acid medium of $\mathrm{pH}=3$ (Figure $3 \mathrm{a}$ ) and in an alkaline medium $\mathrm{pH}=10$ (Figure $3 \mathrm{~b}$ ) are presented below. On the figure $3 b$, in alkaline medium a single peak appears that at the potential Eapp $=0.69 \mathrm{~V}$ (vs $\mathrm{Ag} / \mathrm{AgCl} / \mathrm{KCl}$ ). This peak is irreversible oxidation of indigo carmine (IC) in dehydroindigo carmine (DHIC). The equation of the reaction is given by the relation (1).

IC $\rightarrow$ DHIC +2 e- (1)

These results are in agreement with those Fanjul-Bolado and al [13] and Coulibaly and al [14].
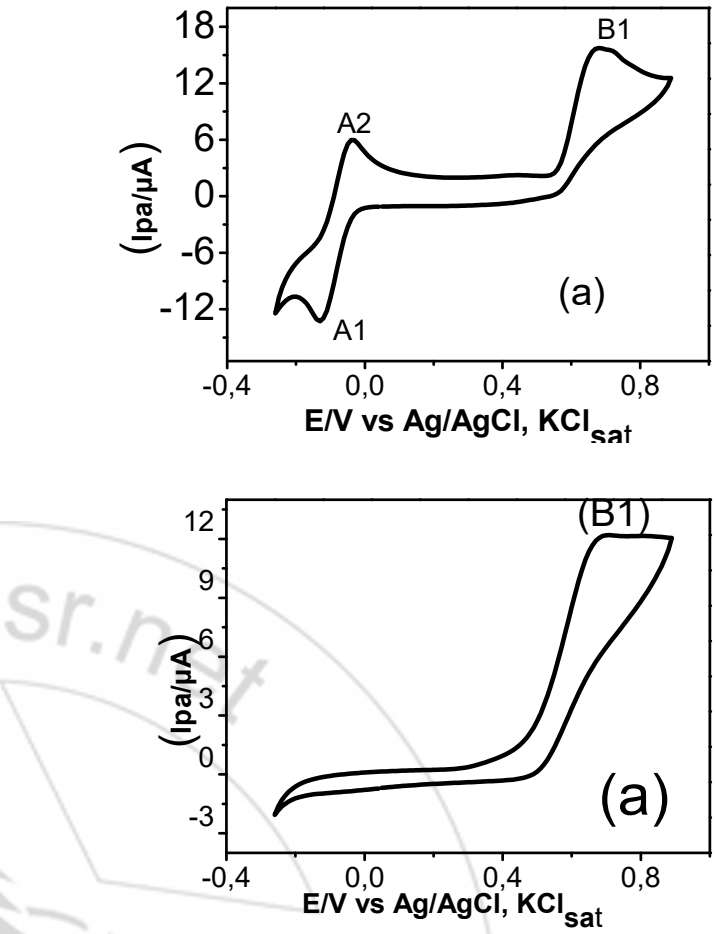

Figure 3: Voltammograms indigo carmine (a) $\mathrm{pH}=3$, scan rate $40 \mathrm{mV} / \mathrm{s}$; (B) $\mathrm{pH}=10$, scan rate $50 \mathrm{mV} / \mathrm{s}$.

The peak current B has for intensity Ip $=9.5 \mu \mathrm{A}$ with the carbon paste electrode (Figure 1b) whereas with the siliconcarbon electrode current value is Ip $=11.2 \mu \mathrm{A}$. This current increase is related to the silicon incorporated into the carbon as also found Walcarius and al on the carbon-silica electrode [20].

Figure 3a shows the voltammogram obtained in acidic medium $\mathrm{pH}=3$. This figure shows three peaks that suggest the existence of redox reaction in the interface solid siliconcarbon composite/ electrolytic solution of indigo carmine. Redox peaks are:

- The peak B1 that reflects the oxidation of indigo carmine in dehydroindigo carmine.

- The Pic A1 that indicates the reduction of indigo carmine in leucoindigo carmine

- The Pic A2 explains the oxidation of indigo carmine in leucoindigo carmine.

These results are in accordance with those of Fanjul-Bolado [13] with the DS SPCEs electrode (DropSens screen-printed carbon electrode) untreated. Instead of the four peaks found with only the carbon paste, as in Coulibalyand al. Here B2 peak disappeares with the electrode where the silicon is incorporated into the carbon as in FanjulBolado who worked with the DS SPCEs electrode. The disappearance of the peak of dehydroindigo carmine's reduction reaction in indigocarmine suggests that the redox reaction is limited by another reaction. 


\section{International Journal of Science and Research (IJSR) \\ ISSN (Online): 2319-7064}

Index Copernicus Value (2013): 6.14 | Impact Factor (2015): 6.391

This reaction is the hydrolysis of the imine group [13]. Electrical quantities that are away from peak potential, the formal potential and the current ratio of one peak A1/A2 reversible calculated are contained in Table 3 .

Table 3: Electrical quantities ofpeak A1/A2 calculated on the composite silicon-carbon electrode scan rate $40 \mathrm{mV} / \mathrm{s}$; in the bracket values found with the carbon paste electrode (EPC).

\begin{tabular}{|l|c|c|c|c|c|c|}
\hline Couple & \multicolumn{2}{|c|}{$\Delta E(\mathrm{mV})$} & \multicolumn{2}{|c|}{$E^{\circ}(\mathrm{mV})$} & \multicolumn{2}{|c|}{ Ia/Ic } \\
\hline A1/A2 & $\mathbf{1 2}$ & $(30)$ & $\mathbf{- 4 0}$ & $(-25)$ & $\mathbf{0 , 5}$ & $(1.07)$ \\
\hline
\end{tabular}

The analysis of table data shows that:

- The formal potential passes of - $25 \mathrm{mV}$ (EPC) at $-40 \mathrm{mV}$ (silicon-carbon electrode).This decrease of the formal potential with embedded silicon suggests strengthening the reducing power of the pair A1/A2. The embedded silicon thus improves the responsiveness of torque A1/A2 facing the metal cations

- Quasi-reversible kinetics of A1/A2 torque is more accelerated $\Delta \mathrm{E}$ from $30 \mathrm{mV}$ to $12 \mathrm{mV}$.

- The current ratio which is less than unity indicates the existence of material transport phenomenon and complex phenomenon coupled to the redox reaction. The response of such an electrode is therefore very dependent on the composition of the paste [20].

\subsubsection{Study based on the number of cycles}

Figure 4 shows the voltammograms obtained with the number of cycles. They show that both in acid medium (Figure 4a) and in a basic medium (figure 4b) the amplitude peak does not vary with increasing number of cycles. The redox reaction products are adsorbed on the electrode surface. They block the surface. There is therefore no access to the active area. On this active surface is formed a silanol film by reaction of silicon with embedded water molecules [21] in addition to the hydrolysis of the imine group [13].
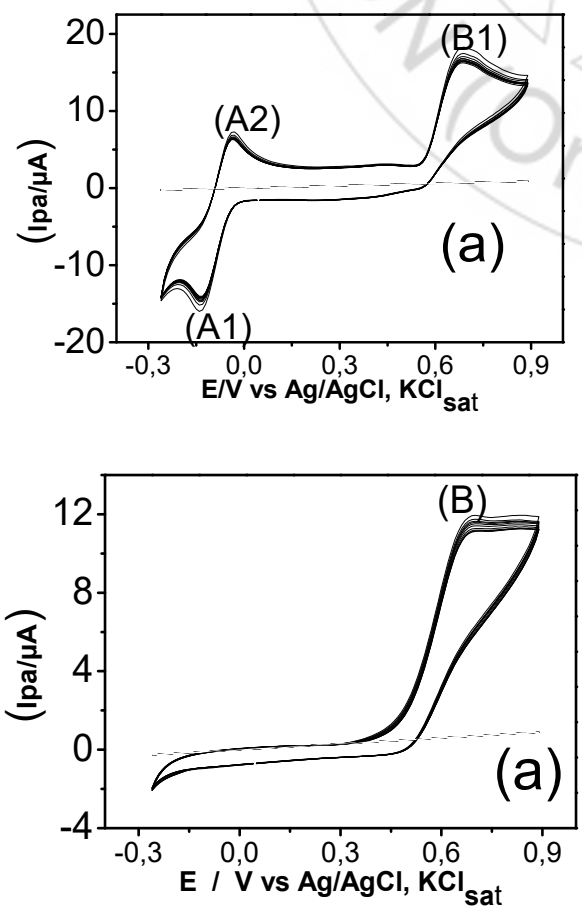

Figure 4:Influence of the number of cycles on the electrochemical behaviour of the indigo carmine $1 \mathrm{mM}$ on the silicon carbon composite electrode, 10 cycles (a) $\mathrm{pH}=3$, scan rate $40 \mathrm{mV} / \mathrm{s}$, (b) $\mathrm{pH}=10$, scan rate $50 \mathrm{mV} / \mathrm{s}$.

The composite electrode is thus subjected to adsorptive material transport phenomena in the interface solid electrode/electrolyte solution.

\subsubsection{Band energy organic polymers.}

Analysis of electrochemical behaviour of indigo carmine in acid medium of $\mathrm{pH}=3$ and basic medium $\mathrm{pH}=10$ shows the formation of polymer. The method of Bredas and al [17] applied to the acid mediumvoltammograms gave energy levels contained in Table 4.

In acid medium, the reaction is reversible. The gap value found for the peak $\mathrm{A} 1 / \mathrm{A} 2$ is $0.05 \mathrm{eV}$. It is less than the gap obtained with the carbon paste. Silicon incorporated into the carbon reduces the gap of the polymer and influences the conductivity of the polymer.

This gap value is close to that of tin telluride, a semiconductor. The value shows that vibration interaction is installed within the polymer network [19]. The value of the HOMO found in basic medium $-5.1 \mathrm{eV}$ for the composite electrode is similar to the value found with the carbon paste electrode.

Table 4: Experimental values of the energy levels as a function of $\mathrm{pH}$

\begin{tabular}{|l|l|l|l|c|c|}
\hline pH & Pics & Potential (V) & $\begin{array}{l}\text { Energy } \\
\text { level }\end{array}$ & $\begin{array}{l}\text { Values } \\
(\mathrm{eV})\end{array}$ & $\begin{array}{c}\text { Gap value } \\
(\mathrm{eV})\end{array}$ \\
\hline \multirow{2}{*}{3} & $\mathrm{~A} 2$ & $-0,1$ & HOMO & -4.5 & \multirow{2}{*}{0.05} \\
\cline { 2 - 5 } & $\mathrm{A} 1$ & $-0,05$ & LUMO & -4.55 & \\
\hline 10 & $\mathrm{~B} 1$ & 0,5 & HOMO & -5.1 & \\
\hline
\end{tabular}

The study with the composite electrode shows redox peaks. The silicon-carbon mixture is an activated material in contact with indigo carmine.

This material can be used for electroanalysis pre-concentrate certain heavy metals such as copper (II) and mercury (II) in differential pulse voltammetry. It can be more active with more complexing surface.

\subsubsection{Formation of the sensitive layer in acid and basic medium.}

The differential pulse voltammograms in Figure 5 shows a plot in alkaline medium $\mathrm{pH}=10$ (b) and in acid medium $\mathrm{pH}$ $=3(\mathrm{a})$.

The activity of the silicon-carbon paste electrode was studied by differential pulse voltammetry in acid medium $\mathrm{pH}=3$ and $\mathrm{pH}=10$ basic medium to see the certain impact of the $\mathrm{pH}$ on the complexation reaction of indigo carmine with mercury (II). 

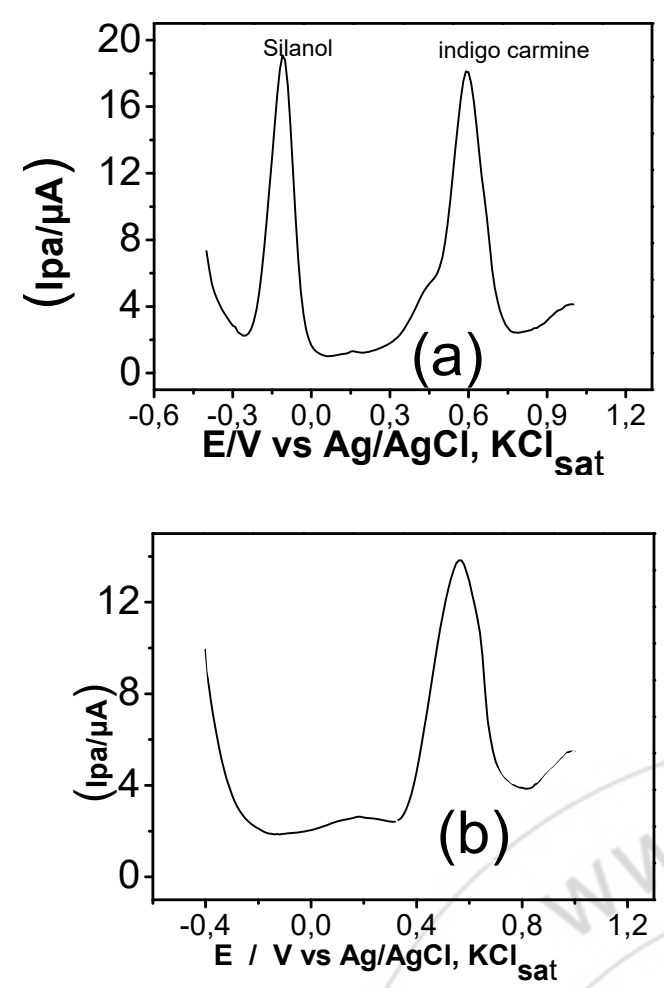

Figure 5:Differential pulse voltammogram of indigo carmine solution $1 \mathrm{mM}$ : (a) $\mathrm{pH}=3$; (b) $\mathrm{pH}=10$, scan rate 30 $\mathrm{mV} / \mathrm{s}$.

In the alkaline medium $\mathrm{pH}=10$ (Figure 5b), a single peak obtained is the oxidation peak of indigo carmine. It appears the potential Eapp $=0.55 \mathrm{~V}(\mathrm{vs} \mathrm{Ag} / \mathrm{AgCl} / \mathrm{KCl})$.

In acid medium $\mathrm{pH}=3$ (Figure 5 a) the curve shows two peaks: a peak at Eappl $=0.56 \mathrm{~V}$ and another peak at Eappl $=$ - $0.11 \mathrm{~V}$ (vs $\mathrm{Ag} / \mathrm{AgCl} / \mathrm{KCl}$ ). The first peak is the formation of a new group at the electrode surface.This compound derives from surface properties due to the composition of the electrode material and the insulating layer paraffin oil [7].

The aqueous solution in contact with the insulating layer gives rise to the silanol groups on its surface. Its groups may be according to the nature of the neutral $\mathrm{pH}$, positively or negatively charged. They are proton $\mathrm{H}^{+}$donor to form the silanolate group that complexes with metal cations in aqueous solution [21].

The second compound is the carmine dehydroindigo. This shows that two competing reactions occur simultaneously in acid to the sensor interface. Control of phenomena at the interface of the sensor is therefore not easy.

We can better control and optimize a single reaction that several reactions occurring simultaneously. Indeed in acid medium there is concurrently forming the silanol group, hydrolysis of the imine group and oxidation reaction of indigo carmine.

The study also shows firstly that when the $\mathrm{pH}$ is less than three, the silanol group continues to form. On the other hand when the $\mathrm{pH}$ increases this group disappears in favour of that of carmine dehydroindigo which peak is maximal in the alkaline middle. For efficiency and selectivity of the sensor so it is advisable to work in alkaline environment $\mathrm{pH}=10$ because at that $\mathrm{pH}$ value was one reaction that you can control. Indigo carmine is still stable at this $\mathrm{pH}$ value [20]. In short, the silicon-carbon composite electrode is modified by indigo carmine by electrochemical adsorption reaction in alkaline medium. It is therefore a sensitive layer having complexing properties [14], [23], [24].

\section{Conclusion}

Sensor design requires inexpensive materials available and that have large complexing properties. The introduction of silicon incorporated into the graphite matrix Electroanalysis meets the selectivity criterion sensitivity and satisfaction in terms of cost. Organo-mineral material produced can be used to complex the mercury with indigo carmine adsorbed to its electrochemical polymerization surface.

\section{Acknowledgements}

This research was funded by PASRES (Programme d'Appui Stratégique à la Recherche Scientifique) through the project «Détection de traces de métaux lourds par des électrodes à pâte de carbone modifiées par des polymères conducteurs: Application dans la zone d'exploitation minière de la région du sud Bandama » (Project number 37).

\section{References}

[1] A.Walcarius, M. Etienne, S. Sayen and B. Lebeau, Electroanalysis 2003, 15,414.

[2] R. Agraz, M. T. Sevilla and L. Hernandez, J, Electroanl. Chem. 1995,390,47.

[3] A.M. Bond, W. Miao, T.D, Smith and J. Jamis, Anal, Chim. Acta 1999, 396, 203

[4] S .Goubert-Renaudin, R. Schneider, A. Walcarius, Tetrahedron Letters, 2007, 48(12), 2113

[5] E.F. Vansant, P. Van Der Voort, K.C. Vrancken, Elsevier, Science, B.V. Amsterdam, 1995, 93, 572.

[6] W. Yantasee, Y. Lin, X. Li, G.E. Fryxell, B.J. Busche, Anal. Chim.Acta(2004), 502(2), 207- 212.

[7] C.Despas, PhDThesisat the University of Henri Poincaré, Nancy I (France), 1998.

[8] A. Walcarius, J. Bessiere ,Electranal. (1997), 9(9), 707-713.

[9] A.Walcarius, C. Despas, J. Bessiere, , A. Anal.Chim.Acta(1999), 385(1-3), 7989.

[10] C. Tiffreau, J. Lutzenkirchen, P. Behra, „J. Colloid Interf. Sci. (1995), 172(1), 82-93.

[11] A. Walcarius, J. Devoy, J. Bessiere, Environ. Sci. Technol. (1999), 33(23), 4278-4284.

[12] J. Wang and A. Walcarius ,J. Electroanal. Chem., 407 (1996), 183-187

[13] P.Fanjul-Bolado,D.Hernândez-

Santos, ElectrochimicaActa 53 (2008) 3635-3642

[14] M.Coulibaly, L.M. Muresanstudiaubbchemia, LVII, 3, 2012 (p. $65-72$ )

[15] Jian.-Bo. He ,Guang-He Ma,. Electrochimica Acta55 (2010) 4845-4850

[16] Brun Mathieu, PhDThesisatthe University of Lyon (France), 2011

[17] BoucharebYoucef, Magisterium chemistry of the University of Mentouri Constantine (Algérie),2012 


\section{International Journal of Science and Research (IJSR) \\ ISSN (Online): 2319-7064}

Index Copernicus Value (2013): 6.14 | Impact Factor (2015): 6.391

[18] J.L. Bredas, R. Silbey, D.X. Boudreux, R.R. Chance, J. Am. Chem. Soc., 105 (1983) 6555

[19] G. Horowitz, University of Paris Diderot, course of organic electronics, 2012-2013

[20] A.WaIcarius, J. Bessière, Electroanalysis, 9(9), 1997,70

[21] Benoit Torbiero, PhDThesisat the "Institut Nationale des sciences appliquées"'of Toulouse (France), 2006,pp 33-34

[22] T.L.Randrianantoandro,Afriquesciences 10(2) (2014) 11798 ISSN 1813-548X :

[23] T.B. Zanoni, A.A. Cardoso, M.V.B. Zanoni, A.A.P. Ferreira, Brazilian Journal of Pharmaceutical Sciences, 2010, 46, 723.

[24] H.Tavallali, E.Shaabanpur, SpectrochimicaActa Part A 89 (2012) 216- 221

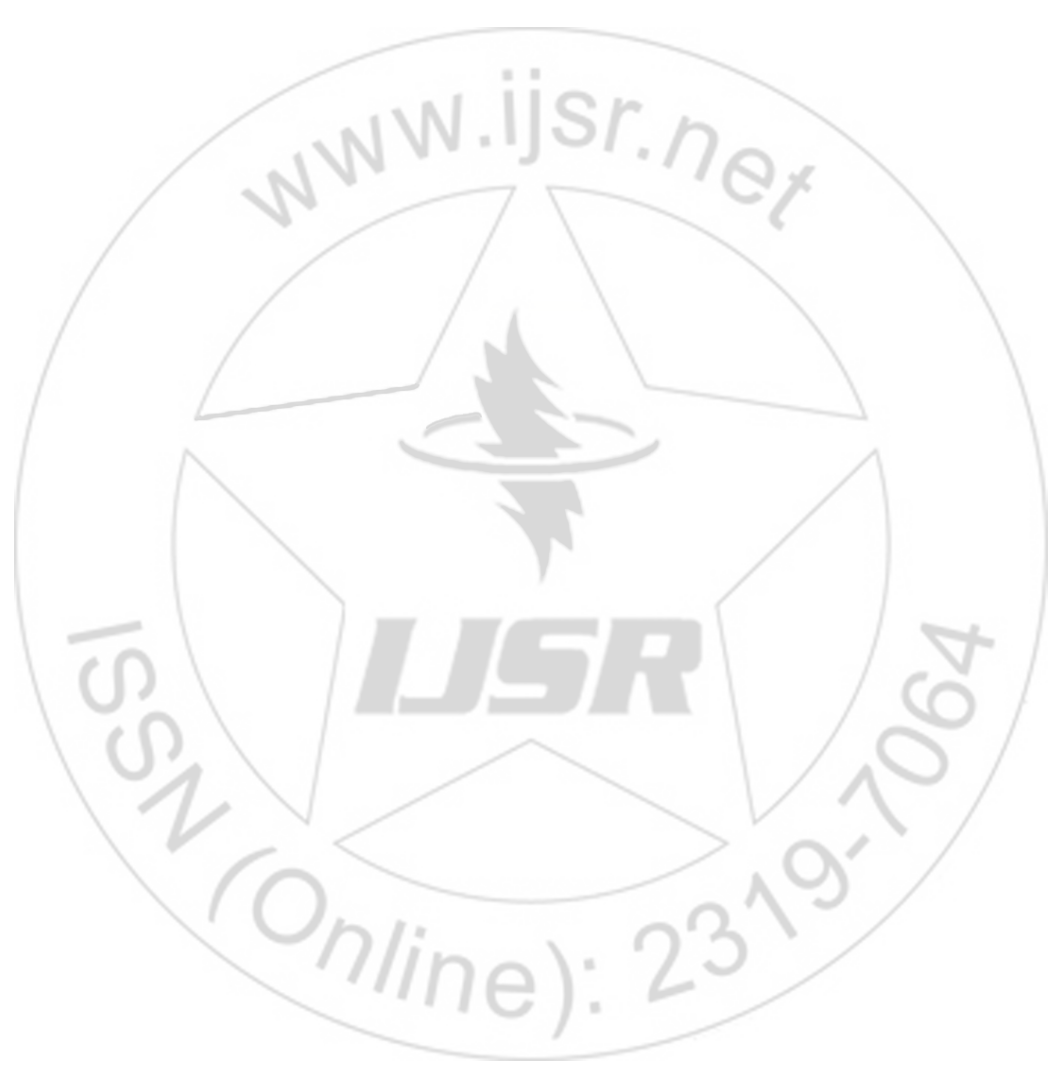

